\title{
Performance of special type heat sink with an integrated synthetic jet actuator
}

\author{
Pawel Gil ${ }^{1, *}$ \\ ${ }^{1}$ Rzeszow University of Technology, The Faculty of Mechanical Engineering and Aeronautics, \\ al. Powstańców Warszawy 8, Rzeszów, 35-959, Poland
}

\begin{abstract}
The performance of special type heat sink with integrated synthetic jet actuator has been presented in this work. Synthetic jet is a flow technique which synthesizes stagnant air to a form of jet. Synthetic jet produces high turbulent flow and thus high heat transfer coefficient can be achieved. Standard heat sink with fan have limited applications in particular in a dusty industrial environment. Therefore, the use of new flow technique is optimistic. The paper presents preliminary results of heat sink thermal power and characteristic temperatures during synthetic jet switched on and off. The results show that under synthetic jet switched on, the dissipated heat is 3.7 times higher than when synthetic jet is switched off.
\end{abstract}

\section{Introduction}

A synthetic jet is produces by a diaphragm oscillating in a cavity with one or more orifices, which produces a volume changing and thus pressure variation. As the diaphragm oscillate, the air is periodically sucked inside and pushed out of the cavity through openings [1]. Under a certain condition [2-3] synthetic jet is formed, which is a train of vortex ring issuing from orifice. The synthetic jet actuators can utilize electroacoustic transducer [4-5] or piezoelectric diaphragm [6]. Since the end of the last century, the synthetic jet has been the subject of interest especially in the field of heat transfer enhancement [7] and flow control [8]. Synthetic jet is widely used for heat removal especially in two geometrical configurations: impinging cooling and with laminar cross flow. Synthetic jet impinging cooling required some distance between synthetic jet actuator orifice and heated plate for effective cooling because for small jet to surface distance, hot air is sucked in synthetic jet actuator cavity reducing thermal power dissipation [9]. One of the unique design solutions of the heat sink is proposed by Mahalingam and Glezer [10] who experimentally investigated performance of synthetic jet ejector heat sink. For natural convection, heat sink thermal resistance was $3.15^{\circ} \mathrm{C} / \mathrm{W}$ and for synthetic jet forced convection was $0.76^{\circ} \mathrm{C} / \mathrm{W}$.

The aim of this paper is to propose a new design of heat sink with an integrated synthetic jet actuator. The synthetic jet cavity and orifices is integrated with heat sink, enabling more compact solutions. In such a geometrical configuration the problem with hot air suction process by synthetic jet actuator is solved. The thermal performance and

\footnotetext{
*Corresponding author: gilpawel@prz.edu.pl
} 
characteristic temperature of heat sink with an integrated synthetic jet actuator was also presented in paper.

\section{Experimental set-up}

The heat sink with integrated synthetic jet actuator designed and manufactured for the purpose of current measurement is presented in Fig. 1. It consist of an loudspeaker (electroacoustic transducer) actuator STX W.18.200.8.FGX of $180 \mathrm{~mm}$ external diameter mounted to heat sink made from aluminium alloy. The heat sink has external diameter of $180 \mathrm{~mm}$ and $30 \mathrm{~mm}$ high, inside cavity is 32 fins and in the side wall there is 16 axisymmetric orifices. The heat transfer area was $0.10 \mathrm{~m}^{2}$. The loudspeaker has nominal impedance $8 \Omega$ and resonance frequency $38 \mathrm{~Hz}$. The audio amplifier Auna CD708 was used to amplify sinusoidal signal from Rigol DG4062 function generation and to power synthetic jet actuator. The working fluid is air. The heat sink with integrated synthetic jet actuator is mounted on circular electric heater powered by DC power supply Sorensen XFR $300 \mathrm{~V}$ and 2 A. Temperature measurement was perform with thermocouple type K. Three thermocouple were fixed to heat sink base and seven thermocouple were used to measurement ambient temperature. The cold junction compensation was realize with Kaye 170 ice point reference. Signals from thermocouple were measure with Keithley 2700 digital multimeter (6.5 digit, 22-Bit) with 7707 all in one I/O module (10 analog input). The resolution of temperature measurement was $0.001^{\circ} \mathrm{C}$ and accuracy better than $0.25^{\circ} \mathrm{C}$. The root mean square voltage, current and frequency of signal feeding electroacoustic transducer and DC voltage and DC current feeding electric heater was measure with Keithley 2700 digital multimeter with 7702 all in one I/O module (20 analog input) (Fig. 2). The accuracy of voltage and current measurement were better than $0.2 \%$. LabVIEW program was utilize for data acquisition. Measurements of heat sink thermal resistance were carried out in a steady state. Each measurement series was 3,600 seconds (1 hour) and included 100 measurements of each parameter.
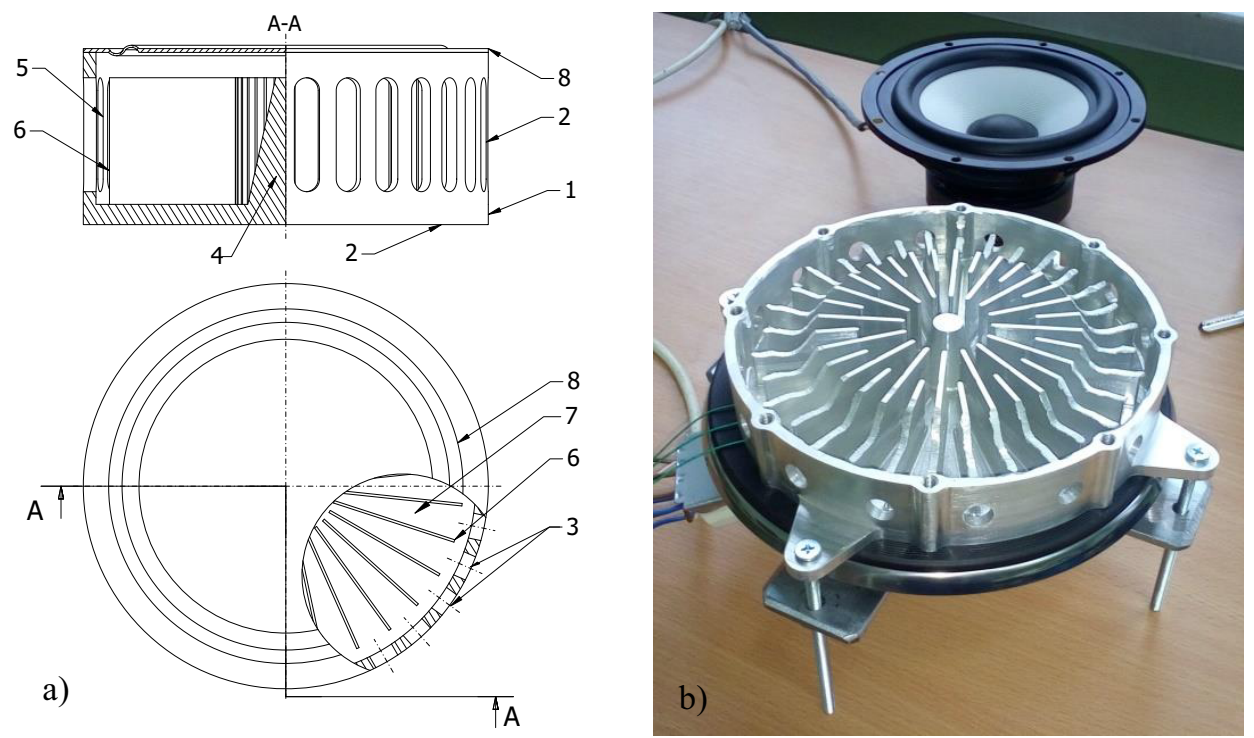

Fig. 1. a) Heat sink with an integrated synthetic jet actuator: 1 - heat sink, 2 - base, 3 - orifices, 4 -inflow steering, 5 - gap, 6 - fins, 7 - duct, 8 - actuator, b) photo of milled heat sink and actuator. 
The synthetic jet actuator was powered by sinusoidal signal with frequency $38 \mathrm{~Hz}$ and root mean square voltage equal $5 \mathrm{~V}$ for each case. The electric power consumed by the loudspeaker was $1.3 \mathrm{~W}$. The heat sink thermal resistance was calculated as:

$$
R=\frac{T-T_{a m b}}{Q}
$$

and

$$
Q=U \cdot I
$$

where:

$T$ - is average heat sink base temperature, ${ }^{\circ} \mathrm{C}$

$T_{\mathrm{amb}}$ - is average ambient temperature, ${ }^{\circ} \mathrm{C}$

$Q$ - thermal power, $\mathrm{W}$

$U-\mathrm{DC}$ voltage drop on electric heater, $\mathrm{V}$

$I-\mathrm{DC}$ electric current feeding electric heater, A.

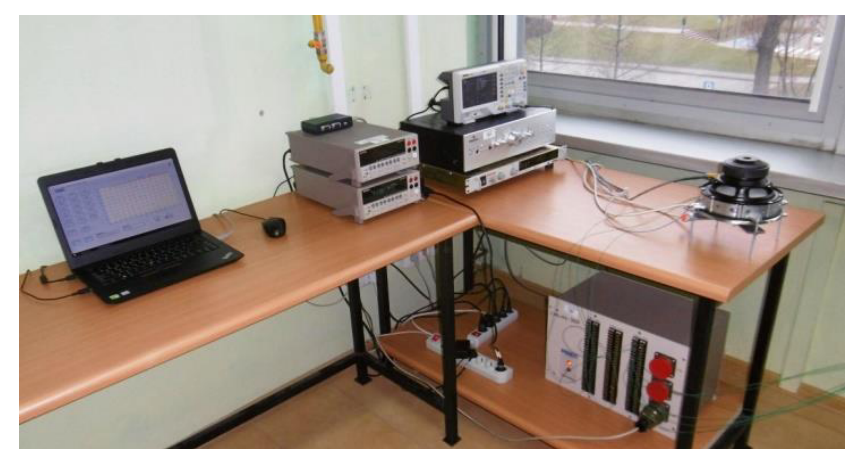

Fig. 2. Experimental set-up.

\section{Results}

The heat sink base temperature variation with time is present in Fig. 3. For the first 10 minutes the DC power supply was switch off, after which was set up at $Q=50 \mathrm{~W}$. The ambient temperature was almost constant during all measurement $T_{\mathrm{amb}} \approx 20^{\circ} \mathrm{C}$. After about $2 \mathrm{~h} 30 \mathrm{~min}$ the steady state for free convection was established, reaching $T \approx 80^{\circ} \mathrm{C}$, then a synthetic jet was switched on and rapid cooling capability can be seen. After next hour the heat sink base temperature was reduced to $T \approx 38^{\circ} \mathrm{C}$.

The heat sink temperatures for free and forced convection at varies thermal power is presented in Fig. 4. The temperature in the first 20 minutes is for free convection after which synthetic jet actuator is switched on (forced convection). For $Q=50 \mathrm{~W}$ heat sink base temperature reduction was $42^{\circ} \mathrm{C}$, for $40 \mathrm{~W}$ and $20 \mathrm{~W}$ the heat sink base temperature reduction were $35^{\circ} \mathrm{C}$ and $19^{\circ} \mathrm{C}$ respectively. 


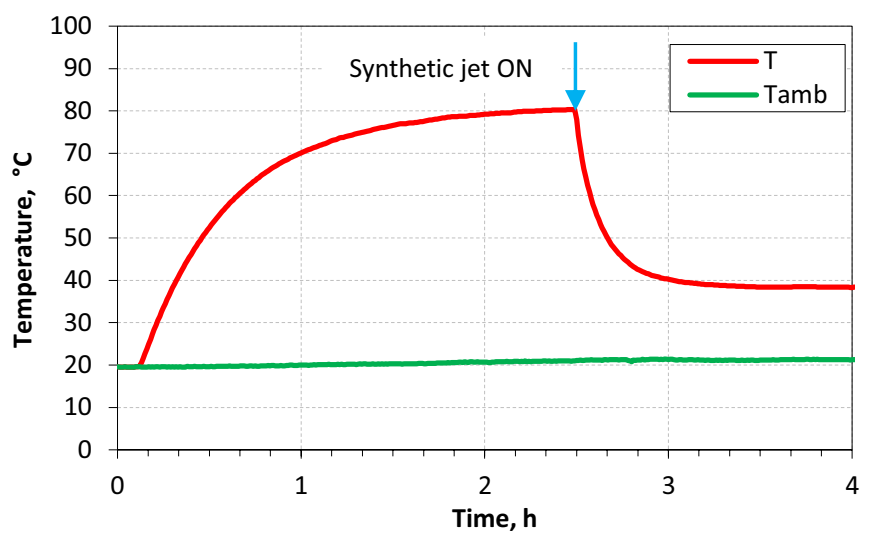

Fig. 3. The heat sink base temperature variation with time.

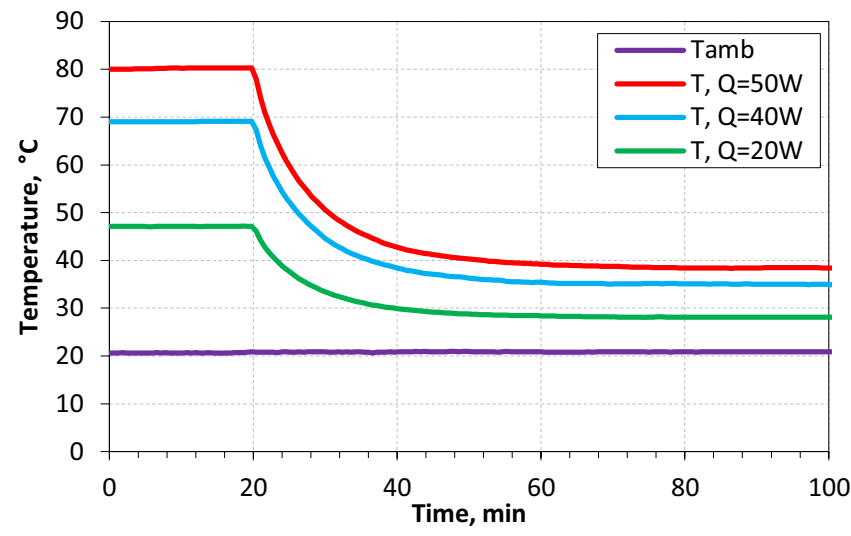

Fig. 4. The heat sink base temperature variation with time for free and forced convection.

The heat sink with integrated synthetic jet actuator thermal performance is presented in Fig. 5. Heat sink thermal resistance for free convection is $R=1.21^{\circ} \mathrm{C} / \mathrm{W}$ while for forced convection is $R=0.33^{\circ} \mathrm{C} / \mathrm{W}$. As can be seen from Fig. 5 for temperature difference $\Delta T=50^{\circ} \mathrm{C}$ (heat sink base temperature $T \approx 70^{\circ} \mathrm{C}$ ) synthetic jet can dissipate more than $Q=152 \mathrm{~W}$ while for free convection $Q=41 \mathrm{~W}$.

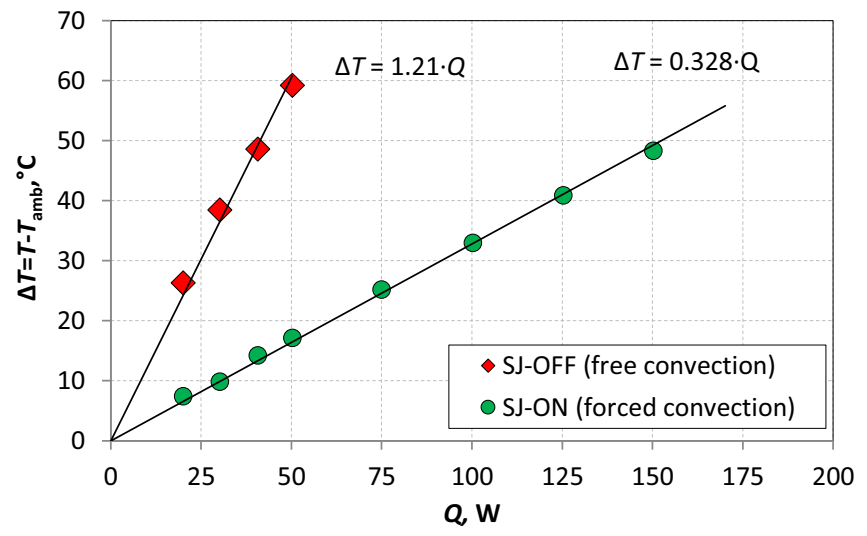

Fig. 5. Heat sink thermal resistance for free and forced convection. 
The new type of heat sink can be used for heat dissipation from industrial electronics components. Especially this design is dedicated for industrial LED lighting. The LED diodes changes about $35 \%$ of the supplied electricity to the usable light and the remaining $65 \%$ is converted into thermal power. Also the temperature of the diode junction also has a significant effect on the parameters of the produced light. The proposed heat dissipation device can be relatively simple continuous controlled for providing heat sink base isothermal operation by changing the amplitude or frequency of signal feeding the actuator. In the industrial environment the dust is also significant factor which reduces a reliability of heat dissipation devices. The device in the presented geometric configuration is not sensitive to dusty environment because the fins are located inside the synthetic jet actuator cavity. In addition, electroacoustic transducers are resistant to dust due to their reciprocating movement.

The energy balance of the device can be represented by coefficient of performance COP. The COP can be defined as the ratio of increased thermal power dissipation to electrical power feeding device. The increased thermal power dissipation can be defined as the difference in power dissipation under forced (synthetic jet on) and free convection:

$$
C O P=\frac{Q_{\text {Forced }}-Q_{\text {Free }}}{P}
$$

where:

$Q_{\text {Forced }}$ - is thermal power under forced convection, W

$Q_{\text {Free }}$ - is thermal power under free convection, W

$P$ - electrical power feeding synthetic jet actuator, W.

The highest $\mathrm{COP}=78$ was achieved for the $Q_{\text {Forced }}=150 \mathrm{~W}$.

\section{Summary}

The thermal performance and new design of special type heat sink with an integrated synthetic jet actuator was presented and discussed in the paper. The heat sink base temperature reduction was achieved for synthetic jet operation. For thermal power $50 \mathrm{~W}$ the temperature drop from about $80^{\circ} \mathrm{C}$ for free convection to $38^{\circ} \mathrm{C}$ for forced convection was achieved. Significantly lower temperatures of the heat sink base result in greater reliability and durability of the electronics. The heat sink thermal resistance was reduced from $R=1.21^{\circ} \mathrm{C} / \mathrm{W}$ to $R=0.33^{\circ} \mathrm{C} / \mathrm{W}$ with the use of synthetic jet. The highest $\mathrm{COP}=78$ was achieved for the tested heat dissipating devices.

\section{References}

1. B. L. Smith, A. Glezer, Phys. Fluids 10, 2281-2297 (1998)

2. R. Holman, Y. Utturkar, R. Mittal, B. L. Smith, L. Cattafesta, AIAA Journal 43, 10, 2110-2116 (2005)

3. P. Gil, J. Fluids Struct. 81, 466-478 (2018)

4. P. Gil, P. Strzelczyk, Exp. Therm Fluid Sci. 76, 163-174 (2016)

5. P. Strzelczyk, P. Gil, J. Phys Conf Ser, 760(1), p. 012029 (2016)

6. Q. Gallas, R. Holman, T. Nishida, B. Carroll, M. Sheplak, L. Cattafesta, AIAA Journal 41, 2, 240-247 (2003) 
7. M. Chaudhari, B. Puranik, A. Agrawal, Int. J. Heat Mass Transfer, 53, 5-6, 057-1069 (2010)

8. P. Gil, J. Appl. Fluid Mech. 12, 1, 293-302 (2019)

9. P. Valiorgue, T. Persoons, A. McGuinn, D. B. Murray, Exp. Therm Fluid Sci. 33, 4, 597-603 (2009)

10. R. Mahalingam, A. Glezer, J. Electron. Packaging 127, 2, 172-177 (2005) 